https://doi.org/10.30910/turkjans.680066

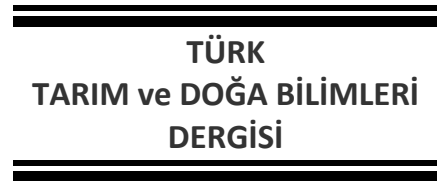

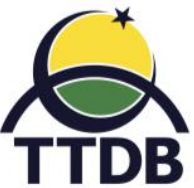

www.dergipark.gov.tr/turkjans

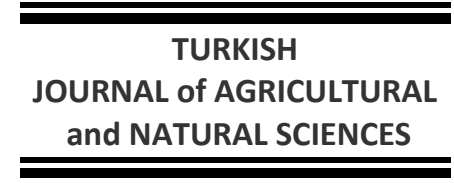

Araştırma Makalesi

\title{
Spesifik Yüzey Alanı Belirlenmesinde Organik Madde, Kireç ve Demir Oksitlerin Uzaklaştırılmasının Önemi
}

\author{
Nurullah ACIR ${ }^{1 *}$, Hikmet GÜNAL ${ }^{2}$
}

${ }^{1}$ Kırşehir Ahi Evran Üniversitesi, Ziraat Fakültesi, Toprak Bilimi ve Bitki Besleme Bölümü, Kırşehir

${ }^{2}$ Tokat Gaziosmanpaşa Üniversitesi, Ziraat Fakültesi, Toprak Bilimi ve Bitki Besleme Bölümü, Tokat

*Sorumlu yazar: nurullah.acir@ahievran.edu.tr

\section{Özet}

Spesifik yüzey alanı (SYA), toprakta gerçekleşen birçok fiziksel ve kimyasal işlemin gerçekleştiği ortamı tanımlayan ve bu nedenle besin döngüsü, üretkenlik, kirleticilerin tutulması ve filtre edilmesi, bozulmaya karşı direnç gösterme ve dayanıklılık gibi toprakların sahip olduğu fonksiyonların gerçekleşmesinde etkin olan bir özelliktir. Gaz (azot gibi) ve polar moleküllerin (etilen glikol mono etilen eter (EGME) gibi) adsorpsiyonları, SYA'nın belirlenmesinde kullanılan yaygın yöntemlerdir. Bu çalışmada, farklı kireç, organik madde ve kil içeriğine sahip 50 adet yüzey toprağının $(0-20 \mathrm{~cm})$ SYA'ına kireç, organik madde ve demir uzaklaştırmasının etkisi araştırılmıştır. Toprak örnekleri, kireç, organik madde ve demir (Fe) oksitlerin uzaklaştırılması amacı ile sırasıyla; amonyum asetat, hidrojen peroksit ve sodyum dithionit ile muamele edilmiş ve her bir uzaklaştırma sonrasında örneklerin SYA'ları belirlenmiştir. Son olarak, tüm uzaklaştırma işlemlerinin ardından kum ve silt parçacıkları mekanik olarak ayrılmış her örneğin kil boyutundaki parçacıklarının SYA değerleri de ölçülmüştür. Toprakların muameleler öncesi hesaplanan ortalama SYA $116.55 \mathrm{~m}^{2} \mathrm{~g}^{-1}$ olup, kireç uzaklaştırılması sonrası elde edilen ortalama SYA değeri $\left(118.50 \mathrm{~m}^{2} \mathrm{~g}^{-1}\right)$ oldukça benzerdir. Organik madde ve demir oksitlerin uzaklaştırıması, toprakların SYA'larının istatistiksel olarak önemli düzeyde artmasına neden olmuştur. Organik madde ve Fe oksitlerin uzaklaştııılması ve killerin SYA değerleri sırasıyla; $163.83 \mathrm{~m}^{2} \mathrm{~g}^{-1}, 180.32 \mathrm{~m}^{2} \mathrm{~g}^{-1}$ ve 307.18 $\mathrm{m}^{2} \mathrm{~g}^{-1}$ dır. Sonuçlar, organik madde ve demir oksitlerin uzaklaştırılmasının topraktaki aktif yüzeylerin ortaya çıkarılmasına katkı sağladığını göstermiştir. Bu nedenle, toprakta birçok özellik için gösterge niteliğinde olan SYA değerinin daha doğru belirlenebilmesi için ön muamelelerin standart olarak uygulanması gerekmektedir.

Anahtar kelimeler: Spesifik yüzey alanı, agregatlaşma, organik madde, kireç, kil, ön muamele.

\section{Importance of Organic matter, Lime and Iron Oxide Removal in Specific Surface Area Measurement}

\begin{abstract}
Specific surface area (SSA) is an important soil property, which helps defining many physical and chemical processes take place in soils; thus, has significant influence on the performance of soil functions such as nutrient cycle, productivity, retention and filtration of contaminants, resistance to resilience. Adsorption of gases (such as nitrogen) and polar molecules (such as ethylene glycol mono ethylene ether (EGME)) are the commonly used methods to determine the SSA. In this study, the effects of organic matter (OM), lime and iron oxide removal on SSA of 50 surface soils $(0-20 \mathrm{~cm})$ with different lime, OM and clay content were investigated. Soil samples were treated with ammonium acetate, hydrogen peroxide and sodium dithionite to remove lime, OM and iron oxides, respectively and the SSA of the samples were determined after each treatment. Finally, the SSA values of the clay-size particles for each soil sample were also measured after mechanically separation of sand and silt particles. Mean SSA determined before the treatments was $116.55 \mathrm{~m}^{2} \mathrm{~g}^{-1}$, which was similar to the mean SSA value obtained after lime removal $\left(118.50 \mathrm{~m}^{2} \mathrm{~g}^{-1}\right)$. The removal of OM and iron oxides resulted in a statistically significant increase in SSA of soils samples. The mean SSA after removal of OM and Fe oxides and
\end{abstract}


the clay particles were $163.83 \mathrm{~m}^{2} \mathrm{~g}^{-1}, 180.32 \mathrm{~m}^{2} \mathrm{~g}^{-1}$ and $307.18 \mathrm{~m}^{2} \mathrm{~g}^{-1}$, respectively. The results showed that removal of $\mathrm{OM}$ and iron oxides contributed to the reveal the active surfaces in the soil. Therefore, pretreatments should be applied as standard in determining the SSA which is an indicator of several soil properties.

Key words: Specific surface area, aggregation, organic matter, lime, clay, pretreatment.

\section{Giriş}

Toprak, bitkilerin ihtiyacı olan besin elementlerinin depolandı̆̆ı, mikro ve makro organizmaların yaşamlarını destekleyen, insan ve hayvan yaşamı için zararlı toksik maddelerin etkilerini azaltan ve kirleticileri filtreleyerek dönüşümlerin gerçekleştiği doğal bir varlıktır. Toprakların bu fonksiyonları yerine getirebilmesi çeşitli genetik (kil tipi ve miktarı gibi) ve dinamik özelikleri (organik madde gibi) ile yakından ilişkilidir (Karlen ve ark. 1997). Kil mineralleri, oksitler ve organik madde toprağın kolloidal yapıya sahip ve fonksiyonların gerçekleşmesinde son derece önemli olan bileşenlerdir (Molina, 2016). Bu üç bileşeni önemli yapan en temel özellik, yapı olarak oldukça küçük olmalarına rağmen sahip oldukları spesifik yüzey alanının (SYA) fazlalığıdır. Bir toprağın SYA'nın yüksek olması, bitkilere sağlanacak besin elementi miktarının da yüksek olması ve/veya zararlı materyallerin toprakta daha fazla filtreleneceği ve tutunacağı anlamına gelmektedir. Bu nedenle, SYA toprakların çeşitli fonksiyonları ile doğrudan ilişki bir özelliktir.

Toprakların SYA üzerine etkili olan en önemli bileşenlerin kolloidal büyüklükteki bileşenlerin doğası olduğu bildirilmiştir (Carter ve ark. 1986; Erşahin ve ark. 2006). Küçük boyutlarından ve yaygın oluşumlarından dolayı özellikle kil mineralleri topraklardaki toplam mineral yüzey alanının büyük bölümünü oluşturmaktadır (Macht ve ark. 2011). Toprakların SYA'nın belirlenmesinde, düşük sıcaklıklarda uygulanan azot gazı $\left(\mathrm{N}_{2}\right)$ (Kahle ve ark. 2002) ve su buharı gibi gaz absorpsiyonu veya etilen glikol mono etilen eter (EGME) (Carter ve ark. 1986), etilen glikol ve metilen mavisi gibi polar moleküllerin absorpsiyonu metotları kullanılmaktadır. Kullanılan materyalin özelliğine bağlı olarak, SYA metotlarının çeşitli avantaj ve dezavantajlarının bulundukları rapor edilmiştir (Jury ve ark. 1991). Örneğin, $N_{2}$ polar olmayan bir moleküldür ve killerin tabakalar arasına giremediğinden dolayı sadece dış yüzeylerin SYA hakkında bilgi vermektedir. Azot gazı kullanımının bu kısıtlaması nedeni ile, killerin tabakalarının arasını da belirleyebilmek için EGME, etilen glikol veya su buharı gibi polar moleküller geliştirilmiştir (Yükselen ve Kaya, 2006). Polar moleküler tabakalar arasına rahatlıkla girebildiği ve bu nedenle genişleme özelliğine sahip minerallerin
SYA'larının belirlenmesinde kullanılabilecekleri bildirilmiş olmasına rağmen, ancak polar moleküllerin farklı düzeyde organik madde içeriğine sahip ve değişik kil minerallerinden oluşmuş topraklarda nasıl sonuç verdiği belirsizliğini korumaktadır (Theng ve ark. 1999).

Toprak özelliklerinden başta kil içeriği ve organik madde olmak üzere, demir oksitler ve kalsiyum karbonat toprakta bulunan mineral ve organik bileşenleri bir araya getirerek agregatlaşmalarını sağlayan bileşenlerdir (Amezketa, 1999; Cañasveras ve ark. 2010). Toprak analizlerinde kullanılan $2 \mathrm{~mm}$ 'den küçük parçacıklar bireysel kum, kil ve silt olabildikleri gibi agregatlaşmış halde de bulunabilirler. Bu nedenle, parçacık büyüklük dağılımı analizi öncesinde, agregatlaşmayı sağlayan bileşenlerin uzaklaştırılmasının daha güvenilir sonuçlar almak için gerekli olduğu bildirilmiştir (Gee ve Bauder, 1986). Bu kapsamda çalışmanın amacı; agregasyonu sağlayan organik madde, demir oksitler ve kireç gibi bileşenlerin uzaklaştırılmasının toprağın spesifik yüzey alanı miktarına etkisini araştırmaktır.

\section{Materyal ve Yöntem Çalışma alanı}

Çalışmada kullanılan toprak örnekleri, Tokat ili sınırları içerisinde yer alan Kazova'da farklı kil, organik madde ve kireç içeriğine sahip 50 noktadan 0-20 cm derinlikten alınmıştır (Şekil 1). Örnekleme alanı olan Kazova'nın büyük bir bölümü, Yeşilırmak nehrinin uzun yıllar taşkınlar ile depoladığı birikintilerin yer aldığı düz-düze yakın tarım arazilerinden oluşmaktadır.

\section{Toprak analizleri}

Parçacık büyüklük dağılımı Gee ve Bauder (1986) tarafından belirtilen hidrometre metoduna göre yapılmıştır. Toprak örneklerinin organik madde analizi "Modifiye Edilmiş Walkley-Black" metoduna (Nelson ve Sommers, 1982), kireç analizi Scheibler kalsimetresi yöntemine (Kacar, 1994), katyon değişim kapasitesi (KDK) analizi 1 N Sodyum asetat yöntemine (Kacar, 1994), agregat stabilitesi (AS) analizi Islak eleme yöntemine göre (Kemper ve Rosenau, 1986) yapılmıştır.

Uzaklaştırma işlemleri öncesi ve sonrasında örneklerin spesifik yüzey alanları (SYA) Cerato ve Lutenegger (2002) tarafından modifiye edilen 
EGME yöntemine göre belirlenmiştir. Polar özellikte olan EGME molekülü parçacıkların etrafında sadece bir kat film oluşturmaktadır. Kullanılan EGME miktarı toplam yüzey alanının göstergesi olarak algılanmakta ve eşitlik 1 kullanılarak, örneklerin SYA hesaplanmıştır (Carter ve ark. 1986).
Eşitlikte

$S Y A=(W a / 0.000286 \times W s)$

SYA; spesifik yüzey alanı $\left(\mathrm{m}^{2} \mathrm{~g}^{-1}\right)$, Wa; örnekte tutulan EGME miktarı, 0,000286; bir gram toprakta tek bir tabaka EGME oluşturmak için kullanılan EGME' nin ağırlığı ve Ws; tartılan toprağın ağırlığıdır (g).
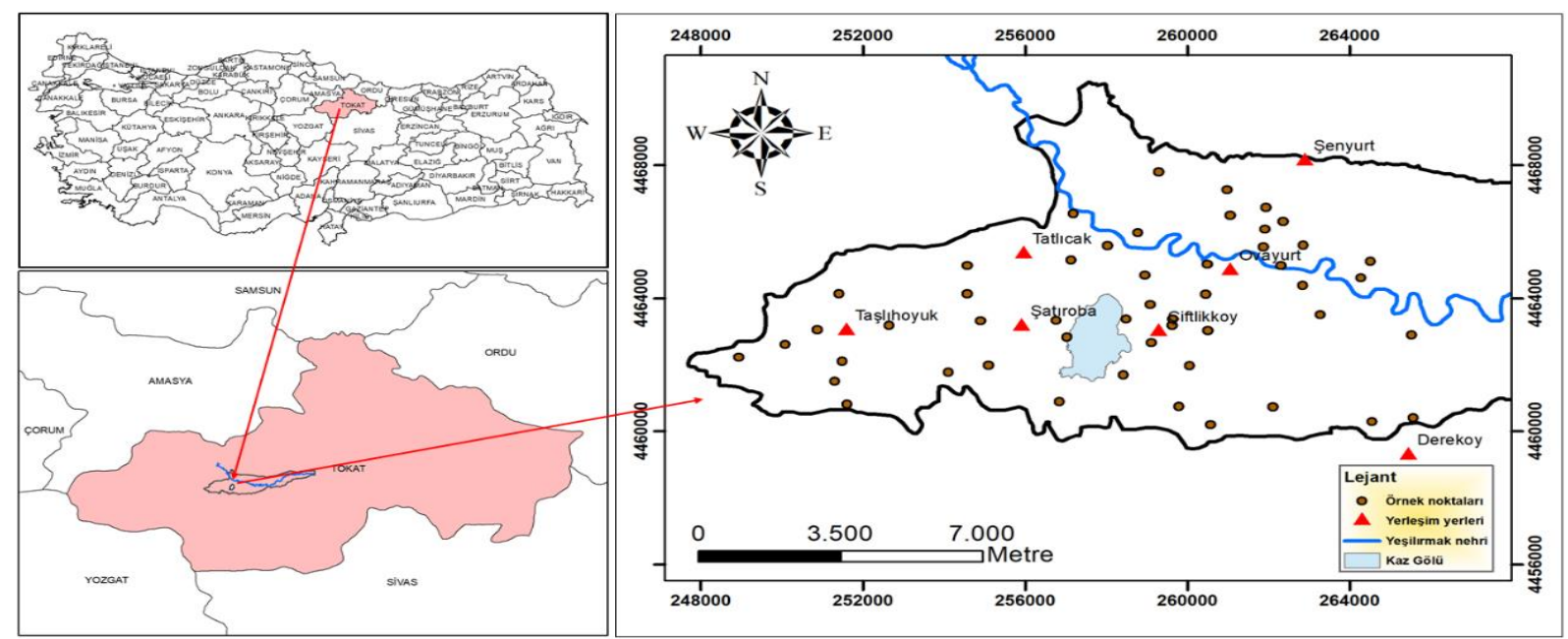

Şekil 1. Çalışma alanını ve örnekleme noktalarını gösteren harita.

Spesifik yüzey alanı analizi öncesi uygulanan uzaklaştırma işlemleri

Toprak örneklerinden kirecin

uzaklaştırılması için pH'sı 5.0'e ayarlanmış olan sodyum asetat $\left(\mathrm{NaC}_{2} \mathrm{H}_{3} \mathrm{O}_{2} \cdot 3 \mathrm{H}_{2} \mathrm{O}\right)$, daha sonra organik maddeyi uzaklaştırmak için hidrojen peroksit $\left(\mathrm{H}_{2} \mathrm{O}_{2}\right)$ ve en sonunda $\mathrm{Fe}$ oksitlerin uzaklaştırılması için sodyum dithionit $\left(\mathrm{Na}_{2} \mathrm{~S}_{2} \mathrm{O}_{4}\right)$ kullanılmıştır. Tüm bu uzaklaştırma işlemlerinden sonra, önce uygun elekler kullanılarak kum parçacıkları kil ve silt'den ayrılmış sonrasında sifonlama yöntemi ile silt ve kil parçacıkları ayırt edilmiştir. Bu işlemlerin her biri aşağıda detaylı olarak açıklanmıştır.

Kireç uzaklaştırılması: Kirecin uzaklaştırılmasında $20 \mathrm{~g} 2 \mathrm{~mm}$ 'lik elekten elenmiş toprak örnekleri Jackson (2005) tarafından belirtilen yönteme göre $1000 \mathrm{ml}^{\prime}$ lik beherlere konularak üzerlerine $\mathrm{pH}$ 5.0'e ayarlanmış $0.5 \mathrm{M}$ sodyum asetat $\left(\mathrm{NaC}_{2} \mathrm{H}_{3} \mathrm{O}_{2} \cdot 3 \mathrm{H}_{2} \mathrm{O}\right)$ çözeltisi eklenmiş ve sıcak su banyosu (yaklaşık 70 $\left.{ }^{\circ} \mathrm{C}\right)$ içerisine konulmuştur. Toprakların kireç içeriklerine göre değişmekle birlikte yaklaşık olarak bir hafta içerisinde karbonatların çözünmeleri ve $\mathrm{CO}_{2}$ çıkışları tamamlanmıştır. Kireç uzaklaştırılan çözeltiye saf su ilave edilmiş, 3 kez saf su 1600 rpm devir ile 10 dakika santrifüj edilmiş ve elde edilen toprağın bir kısmı kurutularak yukarda belirtildiği gibi SYA'nı belirlenmiştir.

Organik madde uzaklaştırılması: Toprakların çözülebilir tuzları veya karbonatları uzaklaştırıldıktan sonra organik madde uzaklaştırılması Kunze ve Dixon (1986) tarafından belirtilen yönteme göre yapılmıştır. Kireç uzaklaştırıldıktan sonra topraklar 2000 ml'lik beherlere alınarak üzerlerine $\% 30$ 'luk hidrojen peroksit $\left(\mathrm{H}_{2} \mathrm{O}_{2}\right)$ çözeltisinden yaklaşık $5 \mathrm{ml}$ eklenmiştir. Bu işlemi daha hızlı hale getirebilmek adına önceki uzaklaştırma işleminde olduğu gibi sıcak su banyosu (yaklaşık $70{ }^{\circ} \mathrm{C}$ ) kullanılmıştır. Köpürme işleminin çok yüksek olabileceği düşünülerek beherlerin ağızları cam kapaklar ile kapatılmıştır. Organik maddenin tamamen parçalanması ve köpürme işleminin durması toprakların organik madde düzeylerine bağlı olmakla birlikte yaklaşık 5 gün sürmüştür. Bir önceki prosedürde olduğu organik madde uzaklaştırılması sonrasında da topraklar $1600 \mathrm{rpm}$ devir ile $10 \mathrm{dk}$ santrifüj edilmiş ve bu işlem $3 \mathrm{kez}$ tekrarlanmıştır. Süzükler döküldükten sonra toprakların bir kısmı SYA analizi için ayrılmış kalan miktarda ise demir uzaklaştırılması işlemine geçilmiştir.

Demir oksitlerin uzaklaştırılması: Kireç ve organik madde uzaklaştırıldıktan sonra demir oksitlerin uzaklaştırılmasında sodyum dithionit $\left(\mathrm{Na}_{2} \mathrm{~S}_{2} \mathrm{O}_{4}\right)$ yöntemi kullanılmıştır (Kunze ve Dixon, 1986). Bu yönteme göre, kireç ve organik maddesi uzaklaştırılmış yaklaşık $10 \mathrm{~g}$ toprak $1000 \mathrm{ml}$ 'lik beherlere konularak üzerlerine öncelikle $100 \mathrm{ml} 0.3$ $\mathrm{M}$ sodyum sitrat dihidrat ve $12.5 \mathrm{ml} 0.5 \mathrm{M}$ sodyum 
bikarbonat çözeltisi eklenmiştir. Daha sonra örnekler yaklaşık $80^{\circ} \mathrm{C}$ sıcak su banyosuna alınarak üzerlerine $2.5 \mathrm{gr}$ sodyum dithionit çözeltisi eklenilerek sürekli olarak 1dakika boyunca karıştırılmıştır. Yaklaşık 15dk sonra örneklerin üzerine $25 \mathrm{ml}$ sodyum klorür eklenmiştir. Topraklarda flokülasyon işlemi yeterli seviyede değil ise örneklere $25 \mathrm{ml}$ aseton eklenmiş ve karıştırmaya devam edilmiştir. Tüm bu işlemler sonrasında elde edilen süspansiyon $1600 \mathrm{rpm}$ devir ile 10 dakika santrifüj edilmiş ve bu işlem $3 \mathrm{kez}$ tekrarlanmıştır. Süzükler döküldükten sonra kalan kısmın bir bölümü SYA belirlenmesi için ayrılmış ve geri kalan kısmı ise kum ve silt parçacıkların uzaklaştırılması işleminde kullanılmıştır.

Kum ve silt uzaklaştırılması: Toprakların kireç, organik madde ve demir oksitleri uzaklaştırıldıktan sonra öncelikle kum büyüklüğündeki parçacıklar uygun elekler kullanılarak uzaklaştırılmıştır. Kil ve silt boyutundaki parçacıklar ise sifonlama yöntemi ile ayrılmıştır. Gee ve Bauder (1979) tarafından belirtilen yönteme göre 1130 ml'lik ölçü silindiri içerisinde eklenen topraklara $10 \mathrm{ml}$ sodyum hegza metafosfat çözeltisi ve saf su eklenilerek 1 L'ye tamamlanmıştır. Yaklaşık 30 saniye boyunca toprak-saf su ve sodyum hegza metafosfat karışımı karıştırılmış ve 12 saat sonra silindirin yüzeyinden $10 \mathrm{~cm}$ 'lik kısmı sifonlanarak biriktirilmiştir. Bu işleme tüm kil boyutundaki parçacıklar sifonlanana kadar devam edilmiştir. Kil içeriğine bağı olmakla birlikte bu işlem yaklaşık 10 gün sürmüştür. Daha sonra elde edilen kil ve saf su süspansiyonları magnezyum klorür kullanılarak floküle edilmiş ve berrak olan su sifonlanarak uzaklaştırılmıştır. Geri kalan kil fraksiyonları $105^{\circ} \mathrm{C}$ 'de buharlaştırılarak kil boyutundaki parçacıklar elde edilmiş ve SYA belirlenmiştir.

\section{İstatistiksel analizler}

Toprak örneklerinin temel özelliklerine ait tanımlayıcı istatistiksel parametreler (en küçük, en büyük, ortalama, standart hata, varyasyon katsayısı (VK), ve çarpıklık değerleri), eşleştirilmiş t-testi ile korelasyon analizleri SPSS programı (SPSS 21) kullanılarak hesaplanmıştır. Uzaklaştırma işlemlerinden sonra elde edilen SYA değerleri eşleştirilmiş t-testi kullanılarak farklılığın istatistiksel olarak önemli olup olmadığına karar verilmiştir.

\section{Bulgular ve Tartışma}

Çalışılan toprakların bazı fiziksel ve kimyasal özelliklerine ait tanımlayıcı istatistik parametreleri Çizelge 1'de verilmiştir. Parçacık büyüklük dağılımının geniş bir aralıkta olması için Yeşilırmak nehrine yakın arazilerden kum içeriği yüksek olan ve nehirden uzak arazilerden ise kil içeriği yüksek olan toprak örnekleri çalışmaya dahil edilmiştir. Çalışılan toprakların kum içeriği \%7.5 ile \%65.0 arasında, kil içeriği ise \%12.5 ile \%75.0 arasında değişmiştir. Toprak örneklerinin organik madde içeriği \%0.83 ile \%5.08 arasında değişmiş ve ortalama organik madde içeriğin \%2.15'dir.

Katyon değişim kapasitesi (KDK), organik madde ve kil içerikleri ile doğrusal bir ilişkiye sahiptir. Kil içeriği ve organik maddenin yüksek olduğu örneklerde KDK 45.32 me $100 \mathrm{~g}^{-1}$ iken kum içeriğinin yüksek ve organik maddenin düşük olduğu örneklerde 8.34 me $100 \mathrm{~g}^{-1}$ olduğu görülmüştür (Çizelge 1). Toprakların kireç içerikleri \%3.21 ile \%28.05 arasında değişkenlik göstermekte olup ortalama \%8.95'dir. Toprakların agregat stabilitesi ortalama \%75.57 olup \%28.39 ila \%100.00 arasında değişkenlik göstermektedir (Çizelge 1). Agregatların dayanıklılığı bireysel parçacıkları bir arada tutan maddeler olan kil içeriği (Brubaker ve ark. 1992), Fe oksitler (Goldberg ve ark. 1988), organik madde (Tisdall ve Oades, 1982) ile değişebilir katyonların miktarı ve tipine (EI Swaify ve ark. 1970) bağlı olarak değişkenlik göstermektedir. Çalışma alanı topraklarının agregatlaşmasını sağlayan organik madde, kireç ve demir oksitler uzaklaştırılmadan ve uzaklaştırıldıktan sonra hesaplanan SYA değerleri Çizelge 2'de verilmiştir. Herhangi bir uzaklaştırma işlemi yapılmadığında toprakların SYA değerleri 47.35 ila $256.85 \mathrm{~m}^{2} \mathrm{~g}^{-1}$ arasında değişmiş olup ortalama $116.55 \quad \mathrm{~m}^{2} \quad \mathrm{~g}^{-1} \mathrm{~d} ı \mathrm{r}$ (Çizelge 2).

Çizelge 1. Toprakların bazı fiziksel ve kimyasal özelliklerine ait tanımlayıcı istatistik sonuçları.

\begin{tabular}{lccccccc}
\hline & Birim & En Küçük & En Büyük & Ortalama & Std. Hata & VK* & Çarpıklık \\
\hline Kum & $\%$ & 7.50 & 65.00 & 23.91 & 11.20 & 46.84 & 1.16 \\
Kil & $\%$ & 12.50 & 75.00 & 44.88 & 13.85 & 30.86 & 0.12 \\
Silt & $\%$ & 12.50 & 51.25 & 31.21 & 8.97 & 28.74 & 0.12 \\
OM* & $\%$ & 0.83 & 5.08 & 2.15 & 1.00 & 46.79 & 1.40 \\
Kireç & $\%$ & 3.21 & 20.85 & 8.95 & 3.29 & 36.70 & 1.65 \\
KDK* & & 8.34 & 45.32 & 24.32 & 9.24 & 37.99 & 0.82 \\
AS* & $\%$ & 28.39 & 100.00 & 75.57 & 19.84 & 26.25 & -0.62 \\
\hline
\end{tabular}

*OM: Organik madde; KDK: Katyon değişim kapasitesi; AS: Agregat stabilitesi, VK: Varyasyon Katsayısı 
Çizelge 2. Uzaklaştırma önce ve sonrasına ait spesifik yüzey alanı değerlerine ait tanımlayıcı istatistik ve eşleştirilmiş t testi sonuçları.

\begin{tabular}{|c|c|c|c|c|c|c|c|c|c|}
\hline & \multirow[b]{2}{*}{ Birim } & \multicolumn{4}{|c|}{ Tanımlayıcı İstatistik } & \multicolumn{4}{|c|}{ Eşleştirilmiş t-testi } \\
\hline & & $\begin{array}{c}\text { En } \\
\text { Küçük }\end{array}$ & $\begin{array}{c}\text { En } \\
\text { Büyük }\end{array}$ & Ort. & $\begin{array}{c}\text { Standart } \\
\text { Hata }\end{array}$ & $\begin{array}{l}\text { SYA* } \\
\text { Tekstür }\end{array}$ & $\begin{array}{c}\text { SYA* } \\
\text { Kireç }\end{array}$ & $\begin{array}{c}\text { SYA* } \\
\text { OM }\end{array}$ & $\begin{array}{c}\text { SYA* } \\
\text { Fe }\end{array}$ \\
\hline $\begin{array}{l}\text { SYA* } \\
\text { Tekstür }\end{array}$ & & 47.35 & 256.85 & 116.55 & 49.07 & - & - & - & - \\
\hline $\begin{array}{c}\text { SYA* } \\
\text { Kireç }\end{array}$ & & 24.92 & 332.50 & 118.50 & 59.02 & $0.67^{o ̈ d}$ & - & - & - \\
\hline $\begin{array}{c}\text { SYA* } \\
\text { OM }\end{array}$ & $\mathrm{m}^{2} \mathrm{~g}^{-1}$ & 46.50 & 307.33 & 163.83 & 65.61 & $0.00 *$ & $0.00^{*}$ & - & - \\
\hline $\begin{array}{l}\text { SYA* } \\
\mathrm{Fe}\end{array}$ & & 69.87 & 460.48 & 180.32 & 73.73 & $0.00 *$ & $0.00^{*}$ & $0.00 *$ & - \\
\hline $\begin{array}{c}\text { SYA* } \\
\text { Kil }\end{array}$ & & 93.12 & 561.51 & 307.18 & 101.86 & $0.00 *$ & $0.00 *$ & $0.00 *$ & $0.00^{*}$ \\
\hline
\end{tabular}

SYA: Spesifik Yüzey Alanı; öd: Önemsiz değer; ${ }^{*} \mathrm{P}<0.05$ düzeyinde istatistiksel olarak önemlidir.

Kireç, organik madde ve demir uzaklaştırılması sonrası elde edilen ortalama SYA değerleri sırasıyla $118.50 \mathrm{~m}^{2} \mathrm{~g}^{-1}, 163.83 \mathrm{~m}^{2} \mathrm{~g}^{-1}$ ve $180.32 \mathrm{~m}^{2} \mathrm{~g}^{-1}$ d $\mathrm{d} \mathrm{r}$. Her üç bileşen uzaklaştırıldıktan sonra, kum ve silt ayrılmış ve örneklerin kil parçacıklarına ait SYA değerleri belirlenmiştir. Kil boyutundaki parçacıkların ortalama SYA değeri $307.18 \mathrm{~m}^{2} \mathrm{~g}^{-1}$ olup, bu değer $93.12 \mathrm{~m}^{2} \mathrm{~g}^{-1}$ ila $561.51 \mathrm{~m}^{2} \mathrm{~g}^{-1}$ arasında değişkenlik göstermektedir. Pennell ve ark. (1995), organik maddenin $\mathrm{H}_{2} \mathrm{O}_{2}$ okside edilmesi sonrası, BET- $\mathrm{N}_{2}$ metoduna göre belirlenen SYA değerlerinde artış olduğunu rapor etmişlerdir. Bu durum organik maddenin parçalanması sonrasında $\mathrm{N}_{2}$ molekülünün daha önce ulaşamadığı yüzeylerin ortaya çıkması ile açıklanmıştır. Gözenekleri tıkayan ve kil agreatlarının üzerini kaplayan organik maddenin uzaklaştırılmasının yeni yüzeylerin ortaya çıkmasına neden olduğu düşünülmektedir. $\mathrm{Bu}$ nedenle de azot gazı adsorpsiyonu ile elde edilen SYA değerlerinin normalden daha düşük olduğu düşünülmüştür (Theng ve ark., 1999). Ancak, organik madde uzaklaştırılmasının, EGME gibi tabakalar arasına rahatlıkla girebildiği düşünülen polar bir molekül ile belirlenen SYA'nın değişimine etkisine ait herhangi bir araştırma bulunmamaktadır. Normal şartlar altında organik madde gibi yüzey alanı yüksek bir maddenin uzaklaştırılması sonrasında yüzey alanında bir düşüş beklenir. Heister (2014), EGME'nin şişme büzülme özelliği yüksek olan killerin tabakaları arasına girmesinde ve organik maddenin polimerik matrisine nüfus etme kabiliyetinde belirsizliklerin olduğunu bildirmektedir. Bu durumda hidrojen peroksit uygulaması sonrasında organik maddenin yüzey alanını tam olarak kaplayamayan EGME'nin organik madde uzaklaştırılması sonrasında daha fazla kil yüzeyini kaplamasından kaynaklandığı düşünülebilir. Ayrıca, kil içeriği yüksek topraklarda polar ya da gaz absorbsiyon yöntemine göre belirlenen SYA miktarı organik madde miktarından çok kil minerallerinin türüne bağlı olarak değişkenlik gösterdiği bildirilmiştir (Heister, 2014).

Topraktaki demir oksitler kil mineralleri üzerinde kaplamalar oluşturabilirler ve bu kaplamaların uzaklaştırılması topraklarda yüzey alanının artmasına neden olabilirler (Borggaard, 1982). Kireç ve organik madde uzaklaştırılmasından sonra agregatlaşma üzerine etkili olan Fe oksitler sodyum dithionit kullanılarak uzaklaştırılmıştır. Fe oksitlerin uzaklaştırılması sonrasında toprakların ortalama SYA $180.32 \mathrm{~m}^{2} \mathrm{~g}^{-1}$ olarak belirlenmiş ve SYA değerlerinin 69.87 ila $460.48 \mathrm{~m}^{2} \mathrm{~g}^{-1}$ arasında değiştiği görülmüştür.

Agregatlaşmada etkili olduğu bilinen organik madde, kireç ve demir oksitler uzaklaştırıldıktan sonra, örneklerin kum ve silt bileşenleri mekanik yöntemler ile ayrılmıştır. Kil büyüklüğündeki parçacıkların ortalama SYA değeri $307.18 \mathrm{~m}^{2} \mathrm{~g}^{-1}$ olup, $93.12 \mathrm{~m}^{2} \mathrm{~g}^{-1}$ ile $561.51 \mathrm{~m}^{2} \mathrm{~g}^{-1}$ arasında değişmiştir. Sayın (1983) kil minerallerinden smektitin SYA'nının $800 \mathrm{~m}^{2} \mathrm{~g}^{-1}$, vermikulitin $750 \mathrm{~m}^{2} \mathrm{~g}^{-1}$ ve kaolinitin $30 \mathrm{~m}^{2} \mathrm{~g}^{-1}$ olduğunu bildirmektedir. Kil büyüklüğündeki mineral parçacıkların SYA değerlerinin incelenmesi ile yapılan örneklerin ki mineralojileri hakkında yapılan değerlendirme, çalışılan toprakların mineralojik bileşimlerinde tek bir mineralin olmadığını, bunun aksine birden çok kil mineralinin karşımı olduğunu göstermektedir. Macht ve ark. (2011) tarafından yürütülen bir çalışmada EGME yöntemi kullanılarak hesaplanan SYA sonuçlarına göre illit kil minerallerinin SYA $112 \mathrm{~m}^{2} \mathrm{~g}^{-1}$, montmorillonit kil minerallerinin yüzey alanı 475 $\mathrm{m}^{2} \mathrm{~g}^{-1}$ olarak rapor edilmiştir.

Farklı uygulamalar neticesinde belirlenen yüzey alanları arasındaki farkın istatistiksel olarak önemli olup olmadığını belirlemek için yapılan eşleştirilmiş t-testi sonuçlarına göre kireç uzaklaştırılması sonrasında elde edilen SYA ile uzaklaştırmanın olmadığı toprakların SYA değerleri 
arasında istatistiksel açıdan önemli bir fark bulunmamaktadır. Ancak, diğer tüm agregasyon faktörlerinin SYA alanı üzerine önemli düzeyde etki yaptığı ve farklılaşmasına $(P<0.05)$ neden olduğu anlaşılmaktadır (Çizelge 2).

Agregasyon üzerine etkili olan bazı fiziksel ve kimyasal özellikler ile agregasyon faktörlerinin uzaklaştırılması öncesi ve sonrasında hesaplanan SYA değerlerine ait korelasyon analizi sonuçları Çizelge 3'de verilmiştir. Elde edilen sonuçlara göre kil içeriği ile agregasyon faktörleri uzaklaştırılması sonrasındaki belirlenen SYA değerleri arasındaki ilişki istatistiksel olarak azalma göstermiştir. Kil içeriği ile muamele öncesi belirlenen SYA değerleri arasında istatistiksel olarak önemli düzeyde $(P<0.01)$ pozitif bir korelasyon $(r=0.72)$ olduğu belirlenmiştir. Agregatlaşmayı sağlayan bileşenlerin uzaklaştırılması sonucu sadece kil büyüklüğündeki parçacıkların SYA değerleri ile kil içeriği arasında istatistiksel olarak önemli $(P<0.01)$ ancak daha düşük düzeyde bir korelasyon $(r=0.47)$ olduğu görülmüştür. Bu sonuçlara göre EGME yöntemi her ne kadar polar bir molekül olarak killerin tabakaları arasına girebildiği düşünülse de organik madde, kireç ve demir oksitler uzaklaştırılmadan yapılacak SYA analizinin gerçeği yansıtmayacağını göstermektedir.

Çizelge 3. Toprakların fiziksel ve kimyasal özellikleri ile uzaklaştırılması öncesi ve sonrası belirlenen SYA değerlerine ait korelasyon testi sonuçları.

\begin{tabular}{|c|c|c|c|c|c|c|c|c|c|c|c|}
\hline & Kum & Kil & Silt & OM & Kireç & KDK & AS & SYA $_{\text {Tekstür }}$ & SYA $_{\text {Kireç }}$ & SYAom & SYA $_{\mathrm{Fe}}$ \\
\hline Kum & 1.00 & & & & & & & & & & \\
\hline Kil & $-0.76^{* *}$ & 1.00 & & & & & & & & & \\
\hline Silt & -0.07 & $-0.59^{* *}$ & 1.00 & & & & & & & & \\
\hline OM & -0.24 & 0.22 & -0.04 & 1.00 & & & & & & & \\
\hline Kireç & -0.01 & 0.21 & $-0.32^{*}$ & 0.21 & 1.00 & & & & & & \\
\hline KDK & $-0.64^{* *}$ & $0.79^{* *}$ & $-0.42^{* *}$ & $0.32^{*}$ & $0.38^{* *}$ & 1.00 & & & & & \\
\hline AS & -0.16 & $0.38^{* *}$ & $-0.39^{* *}$ & $0.52^{* *}$ & 0.26 & $0.51^{* *}$ & 1.00 & & & & \\
\hline SYA $_{\text {Tekstür }}$ & $-0.46^{*}$ & $0.72^{* *}$ & $-0.53^{* *}$ & 0.13 & 0.27 & $0.76^{* *}$ & $0.43^{* *}$ & 1.00 & & & \\
\hline SYA $_{\text {Kireç }}$ & $-0.53^{* *}$ & $0.70^{* *}$ & $-0.42^{* *}$ & 0.09 & $0.39^{* *}$ & $0.75^{* *}$ & $0.39^{* *}$ & $0.84^{* *}$ & 1.00 & & \\
\hline SYAoм. & $-0.35^{*}$ & $0.59^{* *}$ & $-0.46^{* *}$ & 0.06 & $0.43^{* *}$ & $0.69^{* *}$ & $0.46^{* *}$ & $0.49^{* *}$ & $0.64^{* *}$ & 1.00 & \\
\hline $\mathrm{SYA}_{\mathrm{Fe}}$ & -0.25 & $0.51^{* *}$ & $-0.48^{* *}$ & -0.02 & $0.43^{* *}$ & $0.70^{* *}$ & $0.33^{*}$ & $0.47^{* *}$ & $0.58^{* *}$ & $0.91^{* *}$ & 1.00 \\
\hline$S Y A_{K i l}$ & -0.27 & $0.47^{* *}$ & $-0.40^{* *}$ & -0.03 & $0.44^{* *}$ & $0.65^{* *}$ & $0.37^{* *}$ & $0.48^{* *}$ & $0.60^{* *}$ & $0.71^{* *}$ & $0.74^{* *}$ \\
\hline
\end{tabular}

Toprağın toplam negatif yükünün dolayısı ile bu yüklerin bulunduğu yüzeylerin bir göstergesi olarak kabul edilen KDK, tüm SYA sonuçları ile istatistiksel olarak $P<0.01$ düzeyinde önemli bir ilişkiye sahiptir. İstatistiksel açından en yüksek korelasyon Fe oksitlerin uzaklaştırılması ve organik materyallerin uzaklaştırılması ile hesaplanan SYA değerleri arasında ( $r=0.91)$ gerçekleşmiştir.

Spesifik yüzey alanı, KDK başta olmak üzere kil içeriği, su ve besin elementi tutma, kirleticilerin bağlanması ve mikroorganizmalar için yaşam alanı olma gibi çok sayıda özelliğin göstergesi ve hayati faaliyetin gerçekleştiği ortam olduğundan dolayı, güvenilir bir şekilde belirlenmesi son derece önemlidir.

\section{Sonuç ve Öneriler}

Sonuçlar, yüzey alanı belirlenmesinde toprakların organik madde ve Fe oksit gibi mineral parçacıkları bağlayıcı olan bileşenlerinin uzaklaştırılmasının daha güvenilir sonuçlar alınabilmesi adına önemini ortaya koymuştur. Spesifik yüzey alanı sonuçları, polar bir molekül olan EGME'nin organik madde gibi bağlayıcı maddelerin girmiş olduğu tabakalar arasına tam olarak giremediğini göstermektedir. Kireç uzaklaştırması sonucu elde edilen SYA sonuçları, kireç uzaklaştırmanın sonuçları önemli düzeyde etkilemediğini bu nedenle de SYA tayini öncesinde kireç uzaklaştırmanın gerekli olmadığını göstermiştir.

\section{Kaynaklar}

Amezketa, E. 1999. Soil aggregate stability: a review. Journal of sustainable agriculture, 14(2-3): 83-151.

Borggaard, O. 1982. The influence of iron oxides on the surface area of soil. Journal of Soil Science, 33(3): 443-449.

Brubaker, S., Holzhey, C., Brasher, B. 1992. Estimating the water-dispersible clay content of soils. Soil Science Society of America Journal, 56(4), 1226-1232.

Cañasveras, J. C., Barrón, V., Del Campillo, M., Torrent, J., Gómez, J. 2010. Estimation of aggregate stability indices in Mediterranean soils by diffuse reflectance spectroscopy. Geoderma, 158(1-2), 78-84.

Carter, D., Mortland, M., Kemper, W. 1986. Specific Surface. Methods of soil analysis: Part 1- 
Physical and mineralogical methods (methodsofsoilan1): 413-423.

Cerato, A.B., Lutenegger, A.J. 2002. Determination of surface area of fine-grained soils by the ethylene glycol monoethyl ether (EGME) method. Geotech. Test. J. 25: 315-321.

El Swaify, S. A., Ahmed, S., Swindale, L. D. 1970. Effects of adsorbed cations on physical properties of tropical red and tropical black earths: II. Liquid limit, degree of dispersion, and moisture retention. Journal of Soil Science, 21(1), 188-198.

Ersahin, S., Gunal, H., Kutlu, T., Yetgin, B., Coban, S. 2006. Estimating specific surface area and cation exchange capacity in soils using fractal dimension of particle-size distribution. Geoderma, 136(3-4), 588-597. doi:10.1016/j.geoderma.2006.04.014

Gee, G.W., Bauder, J.W. 1986. Particle-size analysis 1. Methods of soil analysis: Part 1-Physical and mineralogical methods (methodsofsoilan1): 383-411.

Gee, G.W., Bauder, J.W. 1979. Particle size analysis by hydrometer: a simplified method for routine textural analysis and a sensitivity test of measurement parameters. Soil Sci. Soc. Am. J. 43: 1004-1007.

Goldberg, S., Suarez, D., Glaubig, R. 1988. Factors affecting clay dispersion and aggregate stability of arid-zone soils. Soil Science, 146(5): 317-325.

Heister, K. 2014. The measurement of the specific surface area of soils by gas and polar liquid adsorption methods limitations and potentials. Geoderma, 216: 75-87.

Jackson, M.L. 2005. Soil chemical analysis: Advanced course. UW-Madison Libraries Parallel Press.

Jury, W., Gardner, W., Gardner, W. 1991. Soil physics. Journal of Environmental Quality (United States), 21(4).

Kacar, B. 1994. Bitki ve Topragın Kimyasal Analizleri. III. Toprak Analizleri. Ü. ZF Eğt. Araşt. ve Gel. Vakfı Yayın (3).

Kahle, M., Kleber, M., Jahn, R. 2002. Predicting carbon content in illitic clay fractions from surface area, cation exchange capacity and dithionite extractable iron. European Journal of Soil Science, 53(4): 639-644.

Karlen, D., Mausbach, M.J., Doran, J., Cline, R., Harris, R., Schuman, G. 1997. Soil quality: a concept, definition, and framework for evaluation (a guest editorial). Soil Science Society of America Journal, 61(1): 4-10.

Kemper, W., Rosenau, R. 1986. Aggregate Stability and Size Distribution 1. Methods of soil analysis: Part 1-Physical and mineralogical methods (methodsofsoilan1), 425-442.

Kunze, G.W., Dixon, J.B. 1986. Pretreatment for mineralogical analysis. Methods of Soil Analysis: Part 1-Physical and Mineralogical Methods, (methodsofsoilan1): 91-100.

Macht, F., Eusterhues, K., Pronk, G. J., Totsche, K.U. 2011. Specific surface area of clay minerals: Comparison between atomic force microscopy measurements and bulk-gas (N2) and -liquid (EGME) adsorption methods. Applied Clay Science, 53(1): 20-26. doi:10.1016/j.clay.2011.04.006

Molina, F.V. 2016. Soil colloids: Properties and ion binding: CRC Press.

Nelson, D., Sommers, L. 1982. Methods of soil analysis. Part, 2: 539-579.

Pennell, K., Abriola, L., Boyd, S. 1995. Surface area of soil organic matter reexamined. Soil Science Society of America Journal, 59(4):1012-1018.

Sayın, M. 1983. Toprak Mineralojisi, Çukurova Üniv. Ziraat Fakültesi Ders Notları (78).

Theng, B.K.G., Ristori, G.G., Santi, C.A., Percival, H.J. 1999. An improved method for determining the specific surface areas of topsoils with varied organic matter content, texture and clay mineral composition. European Journal of Soil Science, 50(2): 309316.

Tisdall, J.M., Oades, J.M. 1982. Organic matter and water stable aggregates in soils. Journal of Soil Science, 33(2), 141-163.

Yukselen, Y., Kaya, A. 2006. Comparison of methods for determining specific surface area of soils. Journal of Geotechnical and Geoenvironmental Engineering, 132(7): 931936. 